\title{
CUENTOS DE LA DIFERENCIA SEXUAL ${ }^{1}$
}

Voy a "tomar la palabra".

Pero antes de "tomar la palabra", antes de esta escena y de este día, hubo otras escenas en las que nos preguntábamos cómo él, cómo ella, cómo tú, cómo nosotros, íbamos a "tomarla". De una escena a la otra, los personajes se preguntaban (quiero decir "le preguntaban a su otro") en voz alta: - ¿Cómo vamos a definir "el orden del día"? (¿Escuchan ustedes la frase vibrar?) —Lo más difícil va a ser la primera introducción. - Nos damos la nota de música, y... - Tenemos que programar esto. - Tengo que encontrar una manera acordada de desacordarme. Tú comienzas, y...-¿Por qué yo?... -Es mejor que seas tú por toda suerte de razones evidentes... -Evidentes... - Tú me precedes...-No, eres tú el que siempre me has...-Tú también me precedes...-Tú me programas. Es decir que eres tú quien define el espacio. - Después de todo, me está bien, es decir, bien lo temo.

-Diferencia de nuestros regímenes de escritura. Voy a hablar de tu manera de andar. De tu manera de persuadirnos para hacernos seguirte. ${ }^{2}$

- Y todo esto en una sola sesión.

- Habría que tratar durante un año...

-Y luego habrá la escena. Quizás voy a hablar de la escena.

-Lo que dice la escena es una cosa...

Ahora, la palabra, la tomo. (N.B.: Somos tres, aquí: él, ustedes, es decir el público, y yo, es decir...)

\footnotetext{
${ }^{1}$ Publicado originalmente en la revista Bordes, 4:5 (1997): 104-120, en traducción de Mara Negrón. Esta traducción ha sido editada por Marta Segarra para la presente edición.

${ }^{2} \mathrm{H}$. Cixous utiliza la expresión "faire marcher" que quiere decir "hacer obedecer" o "tomar el pelo a alguien” (Nota de la Trad.).
} 
Un azar parece haber decidido que soy yo quien comienza. Lo que no quiere decir, claro está, que yo "comienzo".

Digo enseguida: tengo miedo. Mi primer capítulo se titula: "Tener miedo para comenzar".

Para ayudarme, voy a leer dos fragmentos de textos para ser escuchados como la música de la diferencia sexual. Fragmentos que tomé, al azar pero sin azar en dos textos que adoro: uno es un volumen de poemas de Ingeborg Bachmann y el otro La lámpara de Clarice Lispector. El azar: abrí, corté como una naranja no quiero decir como en un juego de cartas-, y encontré lo siguiente. (El hecho de que yo haya encontrado estas páginas significa que: donde quiera que yo me hubiese sumergido o aterrizado, habría encontrado el mismo canto). Al "abrir" Ingeborg Bachmann, encontré "Lo que es cierto":

$[\ldots]$

Lo que es cierto - $\tan$ desvanecido, tan desteñido

en semilla y hoja, en el perezoso lecho de la lengua

un año y otro año y todos los años-

Lo que es cierto, no crea tiempo, compite con él.

[...]

Lo que es cierto le hace surcos a la tierra

sueño y corona y la orden

hincha su peine $y$, lleno de frutos maduros

golpea en ti y sorbe completamente. ${ }^{3}$

\section{Abro al azar La lámpara:}

La joven Virginia es la hermana de un hermano. Hermana y hermano me interesan hoy precisamente. El hermano, Daniel, envió su hermana a pensar. Son adolescentes, quizás doce años. Después de una expedición hacia el pensar, Virginia vuelve:

Al subir la escalera sintió que alguien se movía en el rellano; vio a Daniel observándola, sus ojos eran secos, firmes, no la perdonarían nunca. ¿Qué le diría por la tarde en el claro?¿Qué pensamiento traería ella de la experiencia? El miedo la turbó y le produjo cansancio. Entró en el cuar-

\footnotetext{
${ }^{3}$ Traducción de Víctor Castro. Original alemán: "Was wahr ist, so entsunken, so verwaschen / In Keim und Blatt, im faulen Zungenbett / ein Jahr und noch ein Jahr und alle Jahre - / was wahr ist, schafft nicht Zeit, es macht sie wett. // Was wahr ist, zieht der Erde einen Scheitel, / kämmt Traum und Kranz und die Bestellung aus, / es schwillt sein Kamm und voll gerauften Früchten / schlägt es in dich und trinkt dich gänzlich aus". (Nota de la Ed.)
} 
to, se encogió en la cama. Temblaba con un frío que parecía venir de las entrañas y de un corazón encogido y oscuro; su cabeza continuaba siendo martilleada con una precisión alegre. ¿Estoy loca? [...]. ¿Qué le diría a Daniel? Ahora ya no sabía si había visto el cielo por sí misma como quien ve lo que existe o si había pensado en el cielo y había conseguido inventarlo... Había penetrado en un mundo desconocido y loco, le parecía vagamente que el cielo existía en todos los instantes como algo siempre anterior, siempre presente y quieto... y que sobre él flotaban sus deseos de cosas, sus visiones, los recuerdos, las palabras... su vida. Y subía y adquiría volumen en momentos de silencio dándole también un silencio de pensamientos... ¿ o todo eso valía sólo como una de sus ideas, una invención?¿Ver la verdad sería diferente de inventar la verdad?, después de todo su pensamiento era tan fuerte que no parecía rodeado de ningún otro. (Lispector, 2006: 62)

Entré debajo de La lámpara: Encontré el cielo interior originario, el cielo anterior al pensamiento. Los azares nos escoltan bien: abro: se trata de una verdad que trama su cuestionamiento a partir del cuerpo de una muchacha y entre ese cuerpo y un mundo-de mucho-cuerpo. ¿Y yo, yo la veo o la invento, la "D. S."4? ¿O la "veo"?

Tengo miedo. Espero que este miedo me deje. Escribí hace mucho tiempo pensando en este día: "Lo único que veo son obstáculos, tengo miedo". Esto no ha cambiado. Henos aquí él tú, ella yo y él, en el mismo lugar, no, quiero decir en la misma sala, no, quiero decir a la misma hora. El tiempo es el mismo. Al mismo tiempo y frente a nosotros, no, más bien alrededor de nosotros o más bien en mí - me es difícil por el momento decir "nosotros"- y en él, es decir en ti, la pregunta, es decir, el miedo, esta "historia" de la "diferencia sexual”. ¿O quizás sea un cuento? Quizás es una broma, quizás un juego, y si fuera un cuento de hadas, entonces es la hada quien hace la diferencia, la hada diferencia. Sí, me doy cuenta de que al hablar de ella como si fuera una hada tengo un poquito menos de miedo. Siento que con la ayuda de una hada puedo decir y hacer todo lo que sobrevenga, y sobre todo lo que yo creo y luego pienso, sin temer que lo que "yo pienso", tan pronto dicho, no sea instantáneamente aniquilado por un gran razonamiento, de mi propia razón, no necesariamente la suya, o de denegación. Tengo miedo. ¿Pero por qué?

Porque he aquí que acontece la escena que acontece en los sueños. Una escena de examen: tengo que probar yo y te, ella y él, ellaella y élél, no sin ellaél y

\footnotetext{
${ }^{4}$ Juego de significantes entre "D. S." (siglas de "diferencia sexual") y su pronunciación fonética que hace que escuchemos en el registro oral "déesse" [diosa]. (Nota de la Trad.)
} 
élella, etc. ¿Tengo que probar lo más improbable en el mundo, la verdad, la evidencia?

Voy a tener que fotografiar la diferencia que pasa. La "D. S.", como yo la llamo, cuando silenciosamente escribo. La diosa (que) pasa. La-que-pasa es su nombre.

Clarice Lispector decía: "Ahora quiero fotografiar el perfume", no ella no lo decía, ella lo escribía. Voy a tener que fotografiar el perfume, la diferencia. Voy a tener que dibujar el afuera del afuera, desde el punto de vista del afuera del adentro, y hacer creer al afuera que no es más que un fuera que el dentro está adentro, además voy a estar en contacto con la palabra interior, a menudo condenada al oprobio. ¿No estamos todas locas, todos locos? ¿Por qué, me pregunto, tengo que demostrar hoy, en nuestra época, que los árboles crecen? $\mathrm{O}$ más bien, ¿por qué el árbol tiene que probar que crece? Pero a la vez, al escuchar algunos discursos, y los discursos a menudo son nuestros enemigos: es urgente probar que el árbol crece, que hay diferencia, y al mismo tiempo no sé qué hacer para probarlo con palabras, para decir con palabras algo que es la música sin palabras del goce. Pues voy a tratar, sin embargo, de pintar con palabras esta caverna en la que habito desde que pienso en este coloquio.

Antes del coloquio me había hecho la pregunta de la disposición de la escena, la suya, es decir la tuya y la mía, y todo se tornó peligrosamente cargado, la izquierda la derecha, lo alto lo bajo, la butaca la silla. Me dije: "Tengo miedo de ti", "Juego contigo", lo que ya no es totalmente cierto. Es muy difícil, porque "tú" es ustedes, ahora, mientras que cuando yo pensaba, cuando escribía, ese tú, era él. Yo le decía: tú me eres muy familiar. Te conozco hasta en lo que te es desconocido a ti mismo. (Comienzo a decir cosas peligrosas, pero es imposible de otra manera). Te he leído, te leo, es a ti a quien hablo, aunque hable en esta dirección, frente a mí, yo te veo en tus textos, te veo caminar paso a paso, a paso de indio en tus textos (como camina un indio, a paso de salvaje, quiero decir de animal, todo oídos) y, al caminar silenciosamente, miras hacia todos lados. Y tú prevés. (Permítanme decir “tú", aunque yo me dirija hacia ustedes), Quizás ese "tú prevés" es tu vía, es eso tu prevía, tú avanzas con una previsión y una previdencia.

Con circunspección. Tú avanzas: en círculos, cercando. Jugando con el peligro, el péligro. ${ }^{6}$

A ti, te conozco, he aquí el hombre-nacido, me digo, es evidente, me digo. Quiero decir: el hombre con linaje, he aquí el hijo, hijo de madre, he aquí el padre hijo, padre de hijo, padre de hija-ficción...

\footnotetext{
${ }^{5}$ Juego de palabras entre "prévois" [prevés] y "voie" [vía]. (Nota de la Trad.)

${ }^{6}$ Se escucha en el sustantivo "péril" [peligro] el pronombre masculino "il" [él]. (Nota de la Trad.)
} 
He dicho: "Él es hombre". Digo la verdad, ¿cuál?

Es hombre con especificaciones. Con matices. ¿Cómo hacer el retrato de la diferencia sexual del alma sexuada? Con colores, matices, sonidos, significantes. Hombre en su madurez, ya advertido de las redes de identificación siempre temblorosas e intercambiables entre hombres y mujeres y..., y entre etapas de la maduración masculina, hombre que conserva en sí el tema de la rivalidad masculina, de la fuerza - pero ese tema representado con menos viveza, suavizado-, que ha entendido a partir de su propia experiencia la fragilidad del otro hombre, quiero decir del otro hijo, es decir él mismo, pues ha doblegado algo de la rigidez como lo haría una mujer maternal. La madre en él, es una adquisición. El hijo la ha hecho vacilar. Él es hombre más madre. Es hombre madre, por consiguiente ciego. Es niño. Es superniño: niño de sus niños. Pero primero que nada, para comenzar antes de ti, que estás aquí: he aquí el circunciso $\mathrm{y}$ al decir esto lo único que hago es seguirte. No les estoy diciendo nada nuevo, ya que esto está inscrito, casi como "nombre propio", en todos los textos del que usualmente llamo Derrida cuando él no está.

He aquí el circunciso. Es lo que vino a través de tantos y tantos textos extraordinarios, todos esos textos, aparentemente filosóficos, verdaderamente filosóficos, filosóficos en verdad, que son para mí, primero, un inmenso relato que a la vez vacila y casi encuentra, así como finalmente la empresa autobiográfica o biográfica más peligrosa, más valerosa, más loca de estos tiempos, de esta época. Lo único que hago es ver lo que él enseña y leer lo que escribe: He aquí el circunciso, es lo que vino, con "cis", con "si" y "cí" y circunspección.

He tenido, porque J. D., tú, me lo has dado recientemente, entre las manos un texto extraordinario que tiene un título extraordinario: Circonfession ${ }^{7}$... Lo dejo resonar: circo, con [coño], fesse [nalga], sión, si on [si nosotros], sillon [surco], si on t'oublie ô sion, ${ }^{8}$ los significantes, es él. Si hay algo que se deja escuchar, se deja ver, y que a la vez se esconde en ese texto, es la importancia incalculable en el texto, en el tiempo, en el destino, en la descendencia, en los combates, en la esperanza, llamados Jacques Derrida

de este haber-sido-(circunciso) y de este ser-circunciso,

importancia con ecos inauditos, importancia fascinante de ese acto cometido sobre el cuerpo del recién nacido, que no es todavía y ya es él mismo, de esa extracción adicional, de ese decapar dedicado a un dios poco conocido, de ese destoque, de esa violación, y todo eso antes de sí mismo y sobre sí mismo, de esa letra tallada antes de que él supiera leer, es este ser circunciso. Añado que a

\footnotetext{
7 “Circonfession" es un texto autobiográfico de J. Derrida que se publicó insertado en el libro de Geoffrey Bennington (1991). (Nota de la Ed.)

${ }^{8}$ Alusión al salmo bíblico 137:5 ("Si me olvido de ti, oh Jerusalén, pierda mi diestra su destreza”. (Nota de la Ed.)
} 
medida que hable, ello me conducirá a hacer lo que siempre hace Derrida, a retirar, de otra manera, a desplazar, empujar un poquito hacia el lado, lo que se acaba de decir. La palabra circunciso también.

Tú eres circunciso, digo, por consiguiente, comienzo en el cuerpo, habría podido comenzar de otra manera. Ese cuerpo, tu cuerpo, porque tu texto es constantemente de cuerpo, está firmado, está firmado de mil maneras, en él se habla todo el tiempo de la firma, es un texto que está hecho "a la sangrefirma". 9 Pero van ustedes a decirme: ¿esta historia de ser-circunciso constituye un rasgo de masculinidad? ¿Todos los hombres son circuncisos? Quizás. No lo sé. En todo caso para Jacques, la masculinidad, no, no la masculinidad, él, pues, a quien hicieron esa faena, intentando grabarlo antes de que supiera su nombre, se va por ese sendero que lo conduce hacia la muerte, y luego mucho más allá, claro está, a partir de la escena de la circuncisión. Es por ahí que ello pasa, a través de algo que es - quisiera no decirlo sencillamente- "la membrana de menos como adición”. El (no) más-prepucio. Se trata de un tema de una riqueza infinita, no sólo para nuestras imaginaciones o nuestras experiencias, sino por todo lo que, con un pedacito de piel desaparecido, estirándolo como esa piel cielo de san Agustín de la que tú hablas, Jacques ha podido hacer, transformándola (la membrana) en una especie de inmenso manuscrito. Entonces la membrana-demenos, algo que (estoy hablando de nosotros al mismo tiempo) sería la herida, una herida, de antaño.

¿Herida infligida por quién? Pregunta que recorre en particular este texto de Circonfession - es su respuesta, es su relato, quizás su mito- y aquí viene: la madre. Con circuncisión aparece, entra, aunque había estado siempre ahí, la marca de la madre en el hijo. ¿La madre que corta? Es la madre la que sierra, la madre/sierra. La madre circuncida -y me pregunto entonces: $i$ (todos) los hombres están a la merced? ${ }^{10}$ Quizás. En todo caso, la escena madre-hijo dice una gran parte de lo que a mi modo de ver ocupa la escena de la izquierda (del que se encuentra a mi izquierda hoy), de la diferencia sexual. Esta escena compleja, conocemos sus variantes, el odio del hijo a la madre, y luego, a la inversa, la alianza, el anillo madre-hijo, y para él, para ti algo infinitamente anudado, tejido, y que conmueve profundamente, del orden del amor (hoy también tenía intención de hablar de amor), que no se limita simplemente a decir madre e hijo, sino a un conjunto de situaciones determinantes, apasionantes, situaciones de pasiones, es decir, de sufrimiento, de separación de los inseparables, de olvido de lo inolvidable, comenzando por esta: su madre no lo lee. Es él quien nos lo confía, o sencillamente nos lo dice (aquel a quien su madre no lee).

\footnotetext{
${ }^{9}$ La expresión en francés "à la saignature" es un juego de significantes. Se escucha en francés "la signature" [la firma] y "saigner" [sangrar]. (Nota de la Trad.)

${ }^{10}$ Juego de significantes y significado: “à la merci” [a la merced], pero fonéticamente se escucha en francés “à la mere-scie” [a la madre-sierra]. (Nota de la Trad.)
} 
Para volver a esta historia de circuncisión, me intereso por ella en la medida en que yo no soy circunciso, pero sé que él es capaz de decirme que quizás lo soy, ahí percibo una fuente infinita de meditación, de investigación, de dolor, también de alegría. ¿Y si nosotros estuviéramos todos un poco firmados sin saberlo conscientemente? ¿Y todos en tensión entre herida y placer? Un poco abiertos por - el otro- Pasando por la cuestión de la pérdida y del luto que labra un campo muy vasto en los textos de Jacques, pasando por la cuestión de cómo lograr perder lo que ya se ha perdido, para tener la suerte de perder lo que ya se ha perdido, para tener (siempre) algo que perder (dicho de otra manera, para tener tener, ya que el tener es para ser perdido, el tener está preñado del perder). Porque, en esta escena de desprepuciofloración (me acerco, ustedes lo observarán, de la pulga ${ }^{11}$ ), se podría decir, afirmar, que el circunciso (es) (gana al poder ser) incircuncidable. Pero como sé que estoy en territorio derridiano, a partir del momento en que he dicho esto, espero pronto poder decir, una vez recorrida la circunferencia de la alianza, lo contrario. En cualquier caso, él es circunciso. Puedo atenerme a esa realidad en la carne.

El circunciso es explícitamente diferente. Luego "se siente diferente". Diferente de antes. Y de los "otros". Si todos los hombres son "circuncisos", quizás no sea diferente, mas sin embargo esto comienza así: en tanto que diferente. Y supongo, ya que tengo un hermano circunciso, que uno/él/tú se siente diferente, él se siente, tú te sientes diferente de. Pero diferente a pesar de su voluntad. O sin su voluntad.

¿Y nosotras? Una mujer se siente como diferente. Cuando se habla de diferencia sexual en sociedad, es decir en guerra, la persona que carga la diferencia como un peso, como una pregunta, a menudo, es la mujer. Una mujer entra en escena como la que tiene esa diferencia extraña que solo puede describir en el espacio diferencial en el que va al encuentro de ti. ¿Adónde comienza el sentir la diferencia? ¿Adónde comienza nuestro sentir la diferencia?

El circunciso lo habrá sido entonces en primer lugar a su pesar. Ese a su pesar forma parte de la tensión (de ese texto) que se titula Circonfession. Circunciso diferente. Sin que le pidieran su parecer. Sin que pueda hacer nada. Sin que tú puedas hacer nada. Primeramente. Antes de él. En tanto que circunciso, él es el tema de un libro, la Biblia. Por ese golpe de Libro él comienza a pertenecer al universo rico y complicado de los circuncisos y no-circuncisos. He ahí: está escrito. Circunciso por un golpe de libro. Cercenado. En el cuerpo mismo está tallado el límite entre yo y el otro. Lo que constituye la diferencia, es decir, la incisión de unión, está cincelado en la propia carne de ese yo. El otro muerde en el yo, está escrito. O quizás es el yo quien (se) muerde. En adelante, estará el otro legible en ese cuerpo (¿pero quién otro?).

\footnotetext{
11 "Déprépucelage", en el original, juega con dépucelage [desfloración] y prépuce [prepucio], además de con puce [pulga]. (Nota de la Ed.)
} 
Y para nosotras (mujeres), ¿está escrito? ¿Qué podría encontrar como equivalente? ¿Qué golpe? Nada a mi parecer tan antiguo, ningún acto tan antiguo en nuestra existencia, nada tan anterior. La diferencia-mujer se encuentra localizada, albergada, escondida incluso a nosotras mismas, en el cuerpo, y creo que no está escrito, al menos no con cuchillo, no con estilete, no con dientes. Es misterio carne sin tragedia. Y si hay huella, y si hay escena, no es antes, es más tarde, es mañana, es "cuando yo sea mayor", es para imaginar. Hay relato oral, comienza con la historia que nos cuentan, por ejemplo el anuncio de la regla. Lo que encontraría como memoria del cuerpo, evidentemente muy distinta de la "memoria" imposible de la circuncisión, se situaría ahí, en esa advertencia, un misterio del orden de la carne. Invertimos en el rito prometido del propio cuerpo. Se trata también en ese caso de perder sangre, pero mañana, y la pérdida de esa sangre se vive como una ganancia. Como unas nupcias consigo misma.

La circuncisión permanece como $1^{\circ}$ lo que, tú, no has "visto", lo que no has "vivido", lo que te han dado y que no has podido, tú, recibir, lo que solamente, antes de ser tú, has experimentado, sentido, antes de ser Derrida o J. D.; o Élie, ya que al final tú te enteras y también nos informas de que no solo eres ese sinnúmero de signos, de denominaciones, sino también este, Élie, un nombre judío, dado en el momento en que te fue tomado aquello, que es tuyo y que no es tuyo, o por lo menos que es el tuyo pero que no es, él, Élie, en cambio, inscrito (no se le puede ver por ninguna parte) y además te da la ocasión extraordinaria de darte en francés dos "e", dos marcas de femenino que se añaden a la dote de significantes que es la tuya, Élie, y liga [lie], y lee [lit], 1, i, ella [elle]... ¡Qué suerte tienes! Comenzar con el, elle, aile [ala]... (en secreto).

Esta circuncisión permanece como $2^{\circ}$ lo que se te escapa, como se le escapa a cualquier circunciso que piensa la circuncisión. La circuncisión es tu tesoro, tu fuente fantasma. Medito sobre la extrañeza de esta ausencia, de ese pedazo ausente, de ese menos que es un más, de ese menos-de - de esa fértil ci-catriz-, de ese prepucio que salió volando como una pulga e inatrapable. Pedazo, escena de lo que se ha dado y ha volado, momento en dos sentidos.

Y todo esto se acompaña de la pregunta: ¿quién me ha hecho esto?, que acompasa muchos de los temas de Circonfession. "¿Quién me ha hecho esto?" está en el origen del tema de la ceguera, no veo quién me ha hecho esto, no me veo, no me vi circuncidar. Alguien me hizo esto antes de la vista, cuando todavía no era el supervidente en el que por lo siguiente me convertí.

La escena de la circuncisión es asimismo el origen de la escena de la cena, la escena de esa comida inaudita que nos descubre la absorción de ese pedazo por la persona destinataria. De ahí, uno podría imaginar, sería completa e insuficientemente verdadero, que también surge ese gran trazado de la coupure [el corte] en 
todos los textos de Jacques, de coup-pur de la coupe-pure, ${ }^{12}$ o aun de ese juego de la coup-ture [costura], que encontramos en Glas. Por consiguiente des-coser [en dé-coudre], venir a las manos con la circuncisión habrá sido sin cesar una preocupación de tu escritura.

He dicho: tu tesoro. A condición de que sea el tuyo, y no solo el de Todojudío. ¿Cómo lograr que esa desprepuciofloración sea tuya (te preguntas)? Puesto que si hay reinscripción en tus textos de la escena cuyo autor no eres, la tentativa de volver a encontrar el pedazo de rompecabezas desaparecido no se detiene ahí. ¿Cómo lograr ser el circunciso y no solamente uno de los...? ¿O para ser el circunciso de los circuncisos? ¿Y para traspasar la línea (invisible) de la circuncisión? Para no estar más acá del trazado, no únicamente de un lado, para no estar ligado por ese hilo a la memoria? El sueño sería que pudieras descircuncidarte y re-circuncidarte a voluntad. Puesto que no tienes ningún deseo de borrar. No se trata de perder lo que te aconteció (el evento, el golpe, la escena, el mito, la confiscación, etc.).

Tú amas lo que te acontece.

La astucia sería esta: llega un momento en el que nuestro héroe corta el "hilo" de la circuncisión-en-el-linaje. Después de ti, en tu linaje, no hay circunciso. Y volviendo a mis indios, eres el Último de los circuncisos. El último negado [der-nié]. Eres también el último de los circuncisos, el último de los judíos, el peor de los judíos, el menos judío de los judíos, apenas si lo eres, judío, circunciso, soy el último de los circuncisos, te acusas, te vanaglorias, confiesas. Y el último des-circunciso. Es al menos lo que tú inscribes y es probablemente cierto. El último de los circuncisos, el último que habrá tenido que tratar — pero, claro está, es cierto aunque no totalmente- con esta escena esta fuente este tesoro este dolor, que están siempre ahí y a la vez perdidos. Como lo dices muchas veces en Circonfession y en otros textos, quieres ser el escatólogo. Judío, quieres ser(1o) en griego: el griego es la primera lengua que te hayas dado a ti mismo, a tu lengua, a tus labios, el anti-hebreo. Me entero, pues, que quiere tener la última palabra. “¿La última palabra, quieres tenerla?” me pregunté, justo antes del coloquio, cuando, durante una breve conversación, me dijiste, con mucha naturalidad: "eres tú quien comienza, naturalmente". Se ha tratado por consiguiente, hoy, de entrada, de la primera, de la última, palabra, y de quién la tendrá. De pasársela.

Mas, en el espacio móvil de ese pensamiento cuyo gran animador es en este siglo, jamás corremos el riesgo de tener la una o la otra. Quien tiene la última palabra quizás no tenga la última palabra. Después de la última palabra viene la pos-última palabra. Fíjense en Joyce que calculó durante mucho tiempo la última

\footnotetext{
${ }^{12}$ No traducimos el juego de significante-significado a partir de la palabra "coupure" [corte]. El significante "coupure" se disemina para producir "coup-pur de la coupe pure" [golpe puro de la copa pura] en alusión a la cena. (Nota de la Trad.)
} 
palabra de Ulises, que tenía que ser un sí femenino. Cuando un último yes se calcula durante tanto tiempo, uno se puede preguntar qué significa "ese último" que ha comenzado mucho antes del final.

Ser el último y a la vez jugar con ese final imposible, es un deseo de Jacques, el que lo lleva a formular este enunciado, que va a sobresaltar a todos aquellos que se dicen judíos, en el periodo veinticuatro de su Circonfession: "Soy el fin del judaísmo", citando así uno de sus cuadernos de notas de 1981. Enunciado provocador y verdadero: sí, él es el fin del judaísmo, en ese período veinticuatro, es totalmente convincente. (N.B.: ese texto, que se compone de cincuenta y nueve períodos, tiene por consiguiente reglas, "periods". Cada ciclo está marcado por una sangría y regulado orgánicamente según un ritmo de cuerpo Macintosh.)

Se dice en Circonfession cosas hermosas sobre el judío circunciso que está desnudo, doblemente desnudo. Cito un fragmento de un cuaderno datado de 1981. (Lo que pasa es que ese texto se circunfiesa en varios tiempos, se injerta, se escucha, con voces múltiples, va diciéndose y desdiciéndose en varios idiomas a la misma vez. Siempre se desnuda en la lengua de al lado. Cáscaras y muda. El libro despelleja. Y sangra.)

El Judíocircunciso más desnudo quizás por lo tanto más púdico bajo el suplemento del vestido, más limpio más sucio, ahí en donde el prepucio ya no cubre se protege mucho más de estar expuesto por la interioridad, el seudónimo, la ironía, la hipocresía, el rodeo y desrelevo, de ahí mi tema: prepucio y verdad. La cuestión de saber por quién a través de qué fue impuesta la violencia de la circuncisión, si es una herida traumática y si hay otras, simbólicas o no, en ese lugar en donde el debate fijado en torno a las figuras del padre Freud o de la madre Bettelheim ya no me satisface más...

El título, Circonfession, constituye de por sí un hermoso golpe de gracia. Insinuar además, "Prepucio y verdad", forma parte de la sonrisa disimulada de Jacques Derrida. Escucho también: Prepuciosverdad. Y una variación sobre Dichtung und Wahrheit, en la que Prepucio tomaría el lugar de Poesía. Prepucio sería entonces Poesía (en femenino) con relación a Verdad y tendría relación, como Dichtung, con la invención, con la ficción. Alianza seria y chistosa de ese pedacito (de cuerpo) y de ese "todo" (que — nunca- se aprehende más que en la lengua)...

Prepucio y Verdad. P y V, otra más de esas parejas cuyo secreto tiene él. Y ambos dotados para lo inaprensible y para el sacrificio.

Atelaje inesperado, a la primera lectura, pero luego se revela, se revelan.

A propósito: lo que me gusta de él es la expresión ágil de la verdad —o más bien la carrera hacia la verdad, la manera en que su pensamiento va siempre con cuerpo hacia los objetos para pensar en su flexibilidad, la (re)flexión, la manera 
de reflexionarlo todo (de pensarlo y retomar a pensar otra vez más, etc.); y su manera de no pensar nunca de pie al exterior, y sí en inmersión, en la espiral, pensando el mundo en el mundo, sin separarse de la danza rápida o inmóvil de los seres. Entonces, él piensa "en la verdad", hacia la verdad, gracias a "la verdad", que está siempre entre - entre yo y tú.

Y a propósito, añado: cuando digo "él”, me doy cuenta de que no separo "el hombre", como se dice, de su escrito. Porque es un hombre-que-escribe. Un hombre-que-escribe no es un hombre, es un hombre que va frente a él mismo, va hacia lo más lejano de sí mismo, se adiciona, se mezcla (se corta).

Sí, más desnudo, nadie se encuentra tan desnudo. Desnudez que conduce a repensar la cuestión de lo escondido y lo travestido: cuanto más más desnudo está, más escondido, lo que no significa travestido. La disimulación verdadera es el travestido. (El travestido no es solamente exterior: es interior. Se trata de un travestismo interior que se deja ver, se exhibe.) Tú, no estás travestido, lo que explica que estés escondido. Él está únicamente escondido, desnudo-escondido, además está escondido desnudo exclusivamente por un texto que puede aparecer legible o ilegible según los estados, las horas, los deseos, que sólo parece ilegible por efecto de su rapidez. Un texto que avanza con tanta velocidad, entiendo que pueda deslumbrar y producir un efecto de piel luminosa. Sí, es la rapidez textual la que se asemeja a la astucia: hasta qué punto estás en un mismo instante en otra parte, es que tú sacudes la lengua como un encendedor, como una piedra de fuego, de la que brotan miles de chispas, ¿eres tú esta o aquel? En un instante, dices "el mayor", de Pierre, tu hijo, y en un instante, tu hijo mayor resulta ser tu hermano mayor. Todo sube y baja a la vez. Atribución, posesión, definición, todo se va, todo pasa. Ese es el destino de los habitantes de la Lengua.

La circuncisión es de familia. Circonfession sigue la circulación de la circuncisión entre sus miembros. Es una gran historia de familia que el texto transforma en mito. Esa familia está compuesta de una manera muy particular, es la suya, no la mía. Hay personajes que ahora son bien conocidos, ya que han pasado, a través de muchos libros, a formar parte de la mitología de la lectura de nuestra época. Aquí veo crecer la figura de su madre (no la mía, no la nuestra) asociada a la muerte y a la sobrevivencia, la madre alrededor, al borde, cerca de cuya cabecera va y viene el texto. Preguntándose (tú, yo, el texto) cuál será el último en morir. ¿Quién se quedará con la última muerte, la última palabra? Se trata de una madre conmovedora, profética más allá de la ciencia de las palabras. (La mía también es conmovedora pero de otra manera.) Lo que percibo de su madre, aparte del hecho de ser "una madre", y además de las escenas específicas madre-hijo, es que finalmente, en esas escenas de circunfesión, ella es la única en ser única, en un solo ejemplar, si no me equivoco, puesto que los otros personajes de la familia no son ejemplares únicos, aunque obviamente son únicos a cada momento. Y además esta madre tiene la clave de un momento decisivo en toda esta historia: con ella tú siempre $y$ nunca has tenido la última palabra, puesto que 
ella no te habla tu lengua, ni habla, ni lee el derridiano. Tu madre que sin reconocerte: ¿Jac-quién?, te reconoce: Jackie. Esa que es tu madre-quién. Como en esta frase tan hermosa del período cincuenta: "G., mi madre que desde siempre ya no me escucha". Y que, por lo tanto, antes desde siempre te ha escuchado, un día, una vez, en un antiguamente legendario, prenatal. Y que lleva aquí la letra G. como nombre, el que comparte con la otra G., Geoffrey. Y con toda G. ${ }^{13}$ Es a partir de "mi madre que desde siempre ya no me escucha" que tú escribes, y es a partir de la partida de tu madre hacia la muerte que escribes que no sabes si comenzarás o renunciarás a escribir "a la muerte de mi madre" en el momento de, a la luz de, a fuerza de, a destinación de - tan fuerte y anudado está el lazo tejido de muerte de madre de incertidumbre que tensa el texto, tú que escribes sin saber si has comenzado, a escribir, o a morir, o si no eres tú... y es también a partir de esta suerte bíblica extraordinaria de los nombres propios y de los significantes. Ya que esa madre, que está dotada de algunos nombres, se llama de manera suprema: Esther. Escucho: ¿es terre [tierra]? ¿o taire [callarse]? Y también oigo resonar ese Es familiar que da el tono en el Es gibt alemán.

Me dejo llevar por la S, el sonido S, y llego a:

La escena del sexo, creo que "nos mira", la escena. Del período treinta extraigo esto: "Proyecto: describir mi sexo a través de milenios de judaísmo, microscópicamente, fotográficamente, estereofototípicamente, etc.”. He aquí un proyecto que sólo puede ser de hombre, me digo de entrada, es decir, de sexo de hombre descriptible, fotográficamente, estereofotípicamente, etc.

Sin embargo, dicho proyecto es a la misma vez real y metafórico, a la vez noto ese sueño, deseo, locura, juego, necesidad de enseñar captar enseñar sin poder nunca enseñar puesto que no hay nada que enseñar, su sexcreto, como si tu sexo fuera tu hijo sexcreto. ¿Mas qué quiere decir "mi sexo"? ¿Se trata del órgano, del tuyo, o de toda la especie masculina? ¿Y nosotras que nos llamamos mujeres, tenemos una es-cena del sexo? Para nosotras — quizás me equivoco-, me parece que no se trataría tanto, ya sea fantasmáticamente, realmente, metafóricamente, de enseñar-ver-describir, sino más bien de probar, sentir, ¿qué cosa? La "confinidad". Irse hacia lo que Clarice Lispector llama "las zonas inesperadas", y a partir de aquí voy hacia las profundidades, tengo que abandonar lo exterior.

Otra cosa más, puesto que estoy del lado del cuerpo: este texto está lleno de expresiones, excreciones, secreciones, derramamientos corporales. Pienso que si Derrida es a la vez tan leído tan poco leído, tan amado tan agredido, es porque es

\footnotetext{
${ }^{13}$ En francés a través de la letra "G" se inscribe un juego de significantes con la primera persona del pronombre personal ( $j e$ y y la primera persona del verbo tener ( $\left.j^{\prime} a i\right)$. (Nota de la Trad.)
} 
uno de esos pocos "hombres", o quizás el único, que arriesga su cuerpo activo en el texto. Un movimiento corporal del orden del girar en torno (se) inscribe (en) esta Circonfession. Giras tú mismo en torno a ese pene real y metafórico, pene cegado, herido, curado, resucitado, etc., giras en torno a ese sexo, y simultáneamente, tu mirada se da vuelta y al hacerlo hace girar la nuestra.

¿Y qué haría "una mujer", ahí en donde para ti hay pene? ¿Qué hay para nosotras, por mi parte? Si es que soy una mujer, lo que experimento al escribir, al leer es que hay un interior. No un órgano. Sino la tierra, que tiembla. La noche que jadea. Si trabajo de cuerpo y texto, trabajo (desde) el interior. Pero "mi sexo" es esta tierra interior que estamos tratando de escuchar. Si hay órgano, es el órgano adivinado sentido que funciona como sexo, el corazón. Pero, como dije en otra parte, el corazón es el órgano de goce más misterioso, es el sexo sublime común a ambos "sexos".

Para Élie, la escena textual es erótica, y directamente habitada por escenas sexuales. Una sexualidad sensual, sin ambages, obra en el texto motivando goce y pensamiento. De cierta manera tu texto "sólo piensa en eso". Quiero decir: con la fuerza de, con la ayuda de eso. En el derramamiento. En chuparse la sangre. Tu texto se vierte. Lame la herida. Se circunfiesa, confiesa saborear sus pérdidas.

Por otro lado, del otro lado, al escribirse, desde el momento en que se da a leer, la sexualidad se desplaza en el texto, "realzada", sublimada. El erotismo es cardíaco. El goce es casi siempre cuerpo sublimado. O de todo el cuerpo - como pensativo.

Ya que el cuerpo-que-goza, el sexo, no se encuentra solamente en el cuerpo, sino en el mundo cardíaco, en la tierra cardíaca, en las paredes del cielo y de la noche, en la música que es el canto de la carne. El cuento dice: son las mujeres las que cantan. Un hombre que canta es un ser invadido de mujeres.

Las apariencias engañan. Creemos que las mujeres lloran y que los hombres son secos. Mas, tú, el hombre, sólo piensas en llorar.

¿Quiénes son tus otros, en tus textos? ¿A quién confiesas leer? ¿Quién te nutre? ¿Con quién juegas? Si tomamos la serie: Husserl, Heiddegger, Genet, Hegel, Celan, Blanchot, Freud, P. S., etc... hasta ahí aparentemente masculina. ¿Sin mujeres? Y sin "mujeres" no quiere decir que no haya mujeres en el texto. Porque tienes voces. Hay, lo sabemos, voces de mujeres en ti, eres ventrílocuo. Tenemos el caso/Cendre, por ejemplo.

Está el coro indescifrable, coro de dos corazones, voz a dos voces, pero de una sola música, de La carte postale, está el acorde inseparable - en el- desacorde que tal parece hablar extrañamente con una sola voz. Como si no hubiera más que una sola voz para dos en el luto. Como en el último instante del acto de amor. 
Hace un rato decía: a ti te "conozco", a ti te "veo", porque creo hacerlo. Y de ti espero que me respondas: "No es tan sencillo". Lo no tan sencillo es lo que eres. Es lo que tú has traído a este siglo pensando, hablando, esta actitud alerta que constituye la nosencillez. Tan sencillo no es. No tan sencillo.

Para empezar tenía miedo. También tengo miedo porque contigo no tengo la libertad extraordinaria que nos dan los muertos.

Tengo miedo porque estás vivo y además un vivo que detesta la muerte.

Tengo miedo al hablar de hacer lo que siempre hacemos al hablar, tengo miedo de matar un poco. Desde el momento en que hablamos de una persona viva, la matamos un poco, le damos un poco de vida, pero también le quitamos.

También tengo miedo porque eres casi en cada uno de tus rasgos lo contrario de lo que eres.

Eres todo en punto de cruz. En tanto que judío eres en cruz. Si eres judío es allá donde eres no judío, si eres inocente es allá donde eres culpable, si eres culpable, inocente. Si te sientes seguro, es porque te sientes tan inseguro. Tan feliz tan triste, simultáneamente. Tan humano que allá donde eres tan "hombre" uno puede dudar de que lo seas realmente. Y la cruz al resplandecer constela. Y tú, ahí, hete ahí deslizándote, pasando, sin cesar, sin espinas. Uno no puede aprehender ni siquiera un rasgo. No podemos guardarte rencor. Es por esa razón que con tanta frecuencia te guardan rencor. Es decir, te guardan interés. ¿Por qué? Porque eres el niño que se va en compañía de ella, de la tierra (Esther) por el camino del Petit Bois (que conozco, yo iba en compañía de mi padre), y añades que inventabas historias con ella, llorabas con ella, para estar con ella, y luego debías estar enfermo también para quedarte con ella. Dices cabalmente que no estás para nadie, pero te vemos pasar. Es por eso que te guardan rencor.

Hay una prohibición entre nosotros.

No me mates. No mates.

La prohibición es muda (por consiguiente mucho más prohibición).

Entre nosotros, ¿¿dónde está la verdad? Se encuentra entre nosotros. Y tiene miedo. Tengo miedo y sé que tú tienes miedo. ¿Por dónde asirte puesto que tú eres al momento lo contrario o el otro? Si trato de asirte voy a errar.

He dicho: a ti te conozco, lo que no es más que una creencia, para comenzar a hablar; pero lo que resulta inquietante es que yo no me conozco. Es tan distinto a mí, me digo. Pero sólo puedo decir esto a partir de un sentimiento de semejanza (a mí misma o a ti). La diferencia siempre opera entre nosotros como una (im)posibilidad de semejanza. Las diferencias que componen "la diferencia" las noto en el intercambio de las semejanzas. Además ella está en el intercambio. 
Además pasa - sin parar- del uno al otro. Y vive de los dos. Es nuestro resultante incalculable.

Puedo hablar de él, de ti, de ella, de un ella, de una ella, no puedo hablar de "mí".

Parece que el niño que vio la desnudez del emperador era niña. Es un rumor que corre. Lo que yo sé: las niñas, tanto en los cuentos como en la vida, se asombran del devenir falocrático de los niños. ¿Y cuál es el pequeño que escapa a esa rigidez y glaucosidad? El poeta. Ve a través de la mancha en la córnea. Es porque vive en el mundo-más-allá de la realidad. Llamémosle: el país de la Verdad. La Verdad no existe en realidad. Es nuestra ilusión sublime. En realidad.

Todas las hermanitas han sentido un día a sus hermanos endurecerse y no perdonar más. En verdad... La verdad está en el texto entre nosotros. En el texto que se teje entre los dos. Mas si me preguntaran, como en los cuentos, si me gustaría tener/ser un cuerpo de hombre para probar, diría, claro que sí, para probar me apasionaría conocer el mundo con otro cuerpo, poder después trabajar verdaderamente, de una parte y de otra parte, la diferencia sexual, conocer el aire, las piedras, la tierra, con otros músculos, conocer el misterioso goce masculino, sí, me gustaría conocer, saber ese viaje, y todo lo que lo acompaña, y que veo en este momento a mi izquierda, que presiento, pero que no conozco, y saborear cierto tipo de angustia, de temblor, insurrecciones, depresiones, resurrecciones, arraigamientos en el centro del cuerpo. Pero no lo conoceré nunca. Podría acercarme, allegarme lo más cercanamente posible, entrar en las zonas gobernadas por el corazón en las que puedo convertirme en casi-tú. Podría irme hacia la transfiguración. Puesto que a fuerza de escucharvivir un tú, o de leer un libro de este o de otro, a fuerza de deslizarse a través de la escritura al interior de un pensamiento, y de dejarse leer — es decir, ser leída—, se produce en caso de afinidades, en las paredes del alma una forma de imitación en relieve. Hay algo de ti en mí, por lo menos eso creo - es lo que yo llamo "conocimiento"- pero.

Pero nunca pasaré del otro lado cualquiera que sea la aproximación. Además es en la proximidad, como he dicho, que se perfilan de manera sutil y neta los relieves de la diferencia.

(La "D. S." - no es una región, ni una cosa, ni un espacio preciso entre dos, es el movimiento mismo, la reflexión, el Se, la diosa negativa sin negatividad, lo inaprensible que me toca, que viniendo de lo más cercano me da por destellos a mí misma el imposible yo-otro, hace surgir el tú-que-yo-soy, al contacto del otro.)

¿Y nosotras? El cuerpo-mujer, para mí, es ese lugar de donde, ese suave lugar de donde nacen niñas o niños, humanos, descendientes, ese lugar "debajo de la 
cintura", que parece como dos manos, como mañana ${ }^{14}$, y que tiene más de una memoria, una memoria de lo que ha tenido lugar, una memoria de lo que tendrá lugar. Una memoria, que no es fantasma, sino transmitida, hereditaria, pienso en las mujeres que no han tenido hijos directamente, pero que tienen sin embargo el hijo escrito en la carne, de mujer a madre a abuela, de madre a hija a nieta.

$\mathrm{Al}$ decir todo lo que he dicho, he hecho trampas, a pesar de mí, sin hacerlo adrede. He hablado como si los personajes de esta escena fueran: una mujer, un hombre, evidentemente. Tal escena con tales personajes es sin duda posible, habría un hombre que sería un hombre-sin-duda-alguna, una mujer que sería mujer-sin-duda-alguna. Pero sé por experiencia (sólo sé después de experiencia, es decir después de error) que con frecuencia una "mujer" no es una mujer, ni un un "hombre", un hombre, que con frecuencia una "mujer", un "hombre", es un conjunto de $\mathrm{X}$ elementos. Conozco a una mujer que a la segunda ojeada es un conjunto de cinco niños y una niña. En cuanto a las ojeadas siguientes...

No sé cuál es mi conjunto. ¿Quiénes son yo ${ }^{15}$ ? ¿Pretendo que mi son-yo es mayoritariamente mujer? Experimento un sentimiento inquietante cuando hablo de esos conjuntos. Me parece que en la escena político-social de hoy día son sobre todo las mujeres, más que los hombres, las que son conjuntos ocupados, poblados, naturalizados, injertados, por una cierta cantidad de partes del otro, y que gran parte de los hombres están ocupados por elementos mayoritariamente masculinos. Nuestras identificaciones interiores no se pueden contar, abuelo, nieta, hermano ( astrales...) mas, si pudiéramos hacer la suma de esos conjuntos, el resultado sería curioso; la sociedad estaría compuesta aparentemente mitad de hombres mitad de mujeres más o menos, y, en realidad, de una mayoría de elementos llamados masculinos. Pero en verdad, es decir en secreto, sería bien distinto.

Pero a veces cuando hablo con Jacques, o lo escucho, me digo cosas muy sencillas (porque es él quien se protege del peligro de la sencillez): es verdaderamente un hombre, y yo soy verdaderamente una mujer. Lo único que hay que hacer es ver, lo único que hay que hacer es escuchar, me digo, por consiguiente al menos es un poco cierto. Cuando me digo: es evidente, me acuerdo de lo que él nos recuerda sin cesar, y también a mi manera, me acuerdo de que somos ciegos, que siempre se trata solamente de nuestro punto de vista de ciego, que somos unos ciegos que hacemos nuestro propio retrato, a grandes trazos peligrosamente firmes, y que la sabiduría comienza por saber que no podemos evitar, ciegos como somos, creer ser lo que somos a pesar de saber que no sabemos nada de lo que somos, lo que Shakespeare ya nos había dicho.

\footnotetext{
${ }^{14}$ En francés "deux mains" [dos manos] y "demain" [mañana] se pronuncian casi de la misma manera. (Nota de la Trad.)

15 "Sont-je" [son-yo] es homófono en francés de "songe” [sueño]. (Nota de la Ed.)
} 
Estos tres días de coloquio nos han dado cientos de ejemplos de este género, no creo que nadie aquí pueda contentarse con su simple apariencia, y que muchas veces hemos escuchado hablar una mujer compuesta de tío, de bisnieto, de sobrino, de hermano mayor, etc., y a la misma vez nos conformamos con esta apariencia.

Tú y yo, él y yo, nosotros “escribimos”. “Además”, nos escribimos — nos inventamos. Quiero decir: yo me invento, tú te inventas...

Qué suerte que haya textos. Es en ellos que la "D. S." deja huellas lo bastante duraderas para que tengamos el tiempo, que no tenemos en la realidad, de percibirlas. Lo que no sabemos (no sabemos quiénes-nos son-yo, ni lo que decimos), la lengua lo sabe, sobre todo la lengua escrita, que va con la rapidez lenta de la escritura.

Lo que no sabemos de nosotros mismos, lo escribimos, en nuestro idioma: ahí está, se puede leer. ¡Si pudieramos leernos!

Cómo nosotros dos hacemos algo tan diferente, cómo amamos con tanta pasión la misma persona: la Lengua, de manera diferente, eso también se ve al leer.

Evocaré algunas posiciones del cuerpo-en-escritura. Para mí al comienzo no hay nada. Comienzo sin palabras y con cuerpo. Es un dejarse ir por el fondo, un dejarse hundir en el fondo del ahora, una unión del alma. Esperemos. Esto supone una creencia, inconsciente, no formulada, en una fuerza, una materialidad que va a venir, que se manifestará, una mar subterránea, una corriente que siempre está ahí, que va a levantarse y a llevarme.

Cuando comienzo a "escribir", no escribo, me ovillo, me convierto en un oído, soy un ritmo.

Tú: no conozco tu estado de cuerpo inaugural, cuando estás en tu casa sin testigos. Luego te veo en el libro comenzar con un golpe de palabra. "Alguien" te envia una palabra. La atrapas. Lo que me llama la atención en él, es el gusto por y de la palabra. Tu idioma tiene oído para los ecos más lejanos, los murmullos más antiguos de la palabra.

Digo la palabra. Una palabra. Hay poetas que utilizan las palabras en donde menos uno se lo espera, todas las palabras. Para él, es una palabra que de repente entra, se hace poderosa y vence. Se convierte en algo preciado por haberlo sido de antemano, claro está. La palabra que lo conduce y que él va a conducir hasta el apocalipsis, siempre es una palabra que promete, que viene desde muy lejos y que anuncia un viaje extraordinario. Una palabra es el motor primero. 
A esto viene a añadirse el goce tomado a la sintaxis, es decir a lanosencillez de la lengua. Nunca he visto a nadie sorprender $\tan$ incansablemente las vibraciones y las frecuencias de la lengua. Tal parece que ella baile para él. No olvido que hablo de un "filósofo", mas sin embargo lo que hace bailar su filosofía no es otra cosa que esta pasión, esta avidez, este gusto del juego con la lengua, esta Poesía. La oscilación sexual y textual (es lo mismo), es lo que le deleita. Le da ese aire burlón [mo-queur] (quiero decir mot-cœur, claro está) ${ }^{16}$. Precipitarse sobre la palabra, hacer brotar y errar el sentido, temer el peligro, burlarse de toda certeza...

Pero en mí, en la oscuridad, qué ausencia de palabra para comenzar, solamente la emoción y la música...

Como comienzan nuestros textos - sin que lo sepamos. Aquí indico algunas oberturas, tomadas al azar limitado: en mis estanterías. Extendí la mano:

Ella sería fluida durante toda su vida. Pero lo que había dominado sus contornos y los había atraído a un centro, lo que la había iluminado contra el mundo y le había dado un íntimo poder había sido el secreto. Nunca sabría pensar en él en términos claros, temiendo invadir y disolver su imagen. Sin embargo había formado en su interior un núcleo lejano y vivo, y nunca había perdido la magia; la sostenía en su vaguedad insoluble como la única realidad que para ella siempre debería ser la realidad perdida. (Clarice Lispector, La lámpara)

Esta historia comienza en una noche de marzo, tan oscura como lo es la noche mientras dormimos. Tranquilo, el tiempo transcurría como la luna altísima atravesando el cielo. Hasta que más profundamente tarde también la luna desapareció.

Nada diferenciaba ahora el sueño de Martim del lento jardín sin luna: cuando un hombre duerme tan insondablemente, pasa a no ser más que aquel árbol en pie o el salto de un sapo en la oscuridad.

Algunos árboles habían crecido allí con enraizada calma hasta alcanzar lo más alto de sus propias copas y el límite de su destino. Otros ya habían salido de la tierra como bruscos matorrales. [...] Ese mismo día Martim había permanecido de pie en el balcón intentando, todavía, con inútil obediencia, no perderse nada de lo que sucedía. Pero lo que

\footnotetext{
${ }^{16}$ Juego entre moqueur [burlón] y mot-cœur [palabra-corazón], que se pronuncian igual. (Nota de la Trad.)
} 
sucedía no era mucho: en primer lugar la carretera que se perdía en suspensa polvareda de sol, sólo el jardín apenas observable... (Clarice Lispector, La manzana en la oscuridad)

Es con una alegría tan profunda. Es un aleluya tal. Aleluya, grito, aleluya que se funde con el más oscuro alarido humano de dolor de separación pero que es un grito de felicidad diabólica. Porque ya nadie me ata. Sigo con capacidad de razonar - he estudiado matemáticas, que son la locura de la razón- pero ahora quiero el plasma, quiero alimentarme directamente de la placenta. Tengo un poco de miedo: miedo de entregarme, porque el próximo instante es lo desconocido. ¿El próximo instante está hecho por mí? ¿O se hace solo? Lo hacemos juntos con la respiración. Y con una desenvoltura de torero en la arena. (Clarice Lispector, Agua viva)

La escritura había vuelto, el río, el estrecho río mudo con brazos que cantan, la circulación de la sangre en las venas entre los cuerpos, el diálogo sin palabras de sangre a sangre, sin ninguna noción de las distancias, la corriente mágica llena de palabras mudas que circulan de una comunidad a la otra, de una vida a la otra, la leyenda extraña inaudible sino a través del corazón del uno o del otro, el relato tejiéndose allá arriba, quién lo descifrará, el tejido palpitante de la clandestinidad,

La escritura, ese lazo, ese crecimiento, esa orientación había vuelto,

De nuevo el espacio está lleno de voces, el cuerpo entero es corazón. Lo que faltaba era el país, el puerto, la otra orilla, y a lo lejos la casa desconocida, la hermana que recibiría la carta y la adoptaría. (Hélène Cixous, Jours de l'an)

Hace falta escoger una sanguina. De noche la sangre remonta desde edades antiguas. Todo el mundo vivo tiene sangre que remonta de noche. Para favorecer este remontar, como mi sanguina. El jugo gotea por donde he hablado, por donde entre día y noche grito. La naranja [oranje $]^{17}$ es mi fruto de nacimiento y mi flor profética. La primera vez que corté una palabra era ella. La corté en dos pedazos desiguales, uno más largo, uno más corto. Pelo esta oranje en febrero de 1970. Ya lo había hecho en treinta otros febreros: no hay un febrero en mi vida en que no haya comido la oranje. Está llena de tiempo. (Hélène Cixous, Portrait du soleil)

\footnotetext{
${ }^{17}$ El término orange ocupa un lugar muy relevante en la obra de Hélène Cixous, ya que contiene la palabra "Orán" (su ciudad de nacimiento en Argelia) y el pronombre de la primera persona en francés, "je". (Nota de la Ed.)
} 
¿Qué me dicen esas primeras líneas? Se encuentra el mundo pero es interior. Todo se encuentra inmediatamente en el interior; el relato parte del interior. En mí. Noto fluidez, río, sangre, canto, gritos. El universo de partida es un país común, se le reconoce de un texto al otro. La hora es nocturna y de nacimiento.

En cuanto a los temas que palpitan en el flujo de la escritura (conservar perdido, secreto, instante, límite de lo sin reserva...) Jacques también se ocupa de ellos. Sin embargo dichos temas no persistirán. Solo persistirá el flujo - la frase. Él no abandonará un tema hasta que no lo haya bendecido.

Veamos ahora, cómo comienza él. Tomemos Schibboleth. Al instante estamos en lo esencial.

Una sola vez: la circuncisión sólo tiene lugar una vez.

Así, al menos, se nos dió la apariencia, y la tradición de la apariencia, no digamos del simulacro.

En torno a esta apariencia habremos de dar vueltas. No tanto para cercar o delimitar [circonvenir] alguna verdad de la circuncisión habremos de renunciar a ello por razones esenciales. Sino para dejar más bien que se nos aproxime lo que una vez puede ofrecer de resistencia al pensamiento. $Y$ es de ofrecimiento de lo que se trata y de lo que una resistencia semejante da a pensar. En cuanto a la resistencia, también nos ocuparemos de ella, apuntará [fera signe] a la última guerra, a todas las guerras, la clandestinidad, las líneas de demarcación, la discriminación, los pasaportes y las contraseñas. (Derrida, 2002: 11)

Enseguida comienza aquí el inmenso e incansable trabajo de revelación, de detección, de excavación, de horadaje.

Palabras, ja trabajar! Atravesad los límites.

"Una sola vez. La circuncisión sólo tiene lugar una vez." La frase se asienta. Se afirma. Creemos. Tan pronto se cree, se ha fastidiado. Siguiente párrafo. "Así, al menos, se nos dió la apariencia, y la tradición de la apariencia, no digamos del simulacro." Lo que fue asentado no es más que una apariencia - se retira desde la segunda frase. Tercera frase: "En tomo a esta apariencia habremos de dar vueltas." Manera doble de proceder. Esto es lo que debemos hacer en tomo a la apariencia: les propongo, avanzo, es un deber, y luego vamos a girar. Girar es también el movimiento de su pensamiento. De acuerdo, sigámonos, "giraremos". Al momento llega la rectificación: "No tanto para cercar o delimitar [circonvenir] alguna verdad de la circuncisión - habremos de renunciar a ello por razones esenciales". Un paso. Luego un no paso. Un paso adelante, y se pondera el paso. Un paso adelante, y se afina la dirección. "Sino para dejar más bien que se nos aproxime lo que una vez puede ofrecer de resistencia al pensamiento". Si él nos habla de una vez más de una vez es con el propósito de hacer vacilar nuestra fe en esa vez que diciéndose una no disimula su parecer plural, y lleva sobre sí el 
misterio (legible solamente) de la multiplicación de los únicos. Esto va a ser entonces más de una vez. Así avanza su pensamiento, labrando la lengua, el suelo debajo de sus pies, levantando el campo de minas, y descubrimos que nunca sabemos dónde ponemos los pies, los dedos, los deberes, las palabras, el gusto de la palabra y no solo el gusto de la palabra sino también el cuidado extremo, la alerta a la palabra resistencia y a la palabra ofrecimiento, a lo que una resistencia tal nos da a pensar porque el ofrecimiento conlleva dar, etc. La palabra dada se encuentra desarraigada, interrogada rápidamente.

El pensamiento avanza hacia la verdad haciendo ajustes, por "arrepentimiento". "Arrepentimiento" es un término técnico de dibujo. Un dibujo de $\mathrm{Da}$ Vinci: la cabeza de la Virgen y justo al lado, con otro trazo, otra cabeza de la Virgen y a veces una tercera. Se trata precisamente de ese trabajo de desplazamiento, de ajuste, de corrección que hace el dibujante Derrida, corrección de nuestra incorregible tentación de ver una versión definitiva inmediatamente identificable de la Virgen.

Pero no es su arrepentimiento sino el nuestro el que él inscribe: escribe y al punto corrige nuestra lectura previsiblemente insuficiente. No para de extraviarnos extraviándose con nosotros para iluminarnos mejor. Produce un enunciado y este enunciado no cabe en la lengua.

Otro comienzo, y cuidado con las apariencias. Es La carte postale:

Pueden leer estos envíos como el prefacio de un libro que no he escrito.

Habría tratado desde lo que va de las postas, de los correos de todo género, hasta el psicoanálisis... (Derrida, 1980: 7)

Correos - ¿Qué correo, qué posta?, ¿qué puesto, qué post? Y aquí ya estamos "leyendo" un libro que no ha sido escrito - ¿leemos? Podríamos leer, si tuviéramos la posibilidad, la aptitud o la competencia o el deseo o el tiempo, pero aún no sabemos lo que tenemos, ni si tenemos qué, mas sin embargo antes de saber, y de poder, ya leemos. Así es cómo hacemos lo imposible - sin saberlo. Puesto que es siempre sin saberlo que hacemos lo imposible.

A escondidas el maestro de postas se ríe de nosotros. No he dicho todavía hasta qué punto el texto de J. D. se dirige al otro (a nosotros, a mí), se envía (con placer intenso) y siempre se ríe de nuestros esfuerzos por correr con lo inalcanzable. Él mismo inalcanzable para sí mismo. Se ríe. Mientras que nosotros, los arriba citados, no tenemos la delantera suficiente como para reírnos.

Observen que estoy leyendo textos que los años han separado. Y de golpe me impresiona la insistencia del tema de la apariencia; siempre en relación con el lector, a "ustedes", que son "ustedes y yo". Nos dice: ustedes podrían, ¿no podrían?, yo se lo digo pero no vayan a creerlo... Y por todos sitios aparece la palabra apariencia. ¡Cómo nos advierte! Con palabras multiplicadas. Apariencia, pariencia, parientes, alianza, aparición. Cuidado con la diferencia entre parecer y 
parecer. Por consiguiente, una advertencia pero que no se anuncia como en Clarice Lispector: "Cuidado, esto es una advertencia". Es que, tan pronto estamos en uno de sus textos, estamos en el hostigamiento, en ese recordatorio, que hace jadear su pensamiento: ninguno de los enunciados que encuentren por ese camino es un enunciado al que puedan atenerse, ni yo tampoco, como no sea pasajeramente. Fuerza oscura y alegre que recuerda a todos los mortales su mortalidad: no hay que fiarse de las apariencias, guardémonos de atenernos a lo que sea, ya que atenerse es la mejor manera de no retener nada. Seamos pensando, pasando, participando-al-presente-que-pasa-siguiendo.

Tienes razón, uno nunca puede decir que hay más o menos, de un lado o del otro lado, más dificultades o menos, más o menos femenino, verdad, goce, nadie entre nosotros está por encima de nosotros fuera-de-nosotros-y-en-nosotros para decirlo.

Ahí adonde él escribe y nosotros leemos, estamos bien perdidos, Perdidos, nuestra gran suerte.

Sin embargo, existe un lugar en el pensamiento en el cuerpo, en donde la apariencia cesa. Demasiado oscuro y resplandeciente para leer. No (nos) vemos en pleno goce, gozamos. En donde la carne sabe de otra manera, piensa sin palabras: es porque soy una mujer. Es porque tú eres un hombre. Es porque yo soy un hombre. En donde ella no ve nada más que leer. Únicamente para gozar. En donde nos entendemos sin palabras. En donde Clarice Lispector puede afirmar: "Sé muchas cosas que no sé. Y ustedes también." Y él también. Y yo también.

Hay un momento en el que no estamos ya en el temblor a la vez humilde y orgulloso, orgulloso y humilde de la lengua, sino que solo podemos estar ahí donde se trata de creer. De creerse. Ahí donde, cualesquiera sean los "géneros de las postas", no hay confusión posible entre dos tipos de goce. Y entre el de Derrida, porque es un hombre, quiero decir la escritura de D. que avanza con pasos de hombre, lo que es una bendición, escrito como él escribe y no de otra manera, y el de Clarice-que-escribe-como-una-mujer, lo que es una bendición.

No hay muchos textos que nos permitan soñar con lo que es la diferencia. Yo busco la diferencia máxima porque deseo la exuberancia. Si amo tanto los textos de Clarice Lispector, de Jacques Derrida, es porque son tan hábiles como para dejar ver - a pesar de las apariencias-, quiero decir percibir, vivir, cuerpos sexuados y gozando, más allá del intercambio.

Que haya intercambio, claro está, porque si no, no habría nada en el mundo y no los leeríamos: la intercambiabilidad, el ir al otro, el matenerse-abierto ante el otro, el (intentar) ponerse-en-el-lugar-del otro está en función de la generosidad de cada uno. Pero también hay una parte que no se puede intercambiar - lo que no quiere decir que sea imperceptible: una parte de ti que permanece siempre prometida, solamente prometida, por suerte únicamente prometida. 
¿Cómo los leo, a él, a ella, a élie? Los sigo siendo, los vivo, saboreando en el texto de J. D. la gran ajenidad familiar sin embargo (he aquí el texto que "yo sigo siendo" hasta el final de mí misma, y, más allá, es él), saboreando en el texto de C. L. la gran familiaridad singular sin embargo (he aquí el texto que "yo sigo siendo" hasta el final de mí misma, y, más allá, la sigo siendo aún)...

Traducción de MARA NEGRÓN

\section{REFERENCIAS BIBLIOGRÁFICAS}

Cixous, Hélène (1974), Portrait du soleil, París, Des Femmes-Antoinette Fouque.

-(1990), Jours de l'an, París, Des Femmes-Antoinette Fouque.

Derrida, Jacques (1980), La carte postale: De Socrate à Freud et au-delà, París, Flammarion.

-(1991) “Circonfession”, Jacques Derrida, Geoffrey Bennington, París, Le Seuil.

-(2002), Schibboleth. Para Paul Celan, Jorge Pérez de Tudela (trad.), Madrid, Arena Libros.

Lispector, Clarice (2003), La manzana en la oscuridad, Elena Losada (trad.), Madrid, Siruela.

-(2004), Agua viva, Elena Losada (trad.), Madrid, Siruela.

-(2006), La lámpara, Elena Losada (trad.), Madrid, Siruela. 